\title{
Chronotope image in the novel "Ulugbek treasure" by Odil Yakubov
}

\author{
Rahimov Zokir Azimovich ${ }^{1}$ \\ ${ }^{1}$ Associate Professor of Fergana State University, \\ candidate of philological sciences
}

\begin{abstract}
In the novel "The Treasure of Ulugbek" by the talented writer Odil Yakubov is based on the formation of the world of artistic images in the dialectical unity of social environment, historical time, space through artistic time and time, ie chronotope. In the depiction of reality in the work, the character of the historical image and the expression of mental anguish in space and time are logically analyzed and certain conclusions are made.

Keywords: space, time (chronotope), artistic interpretation, psychologism, artistic hero, historical figure, writing skills.

\section{Introduction}

The evolution of human thought demonstrates a variety of artistic concepts. The work of art carries the main idea of a certain period, promotes and absorbs it. It is through the individuals who embody this feature, that is, through the heroes of the period, that the reality of the creative period emerges. A person who embodies the leading features of the period, in turn, is formed and acts under the influence of family, society, environment and historical reality. Mature individuals of their time have a direct impact on every event, environment, and circumstance. As the writer depicts life events, he creates artistic characters, thereby demonstrating his skill. The writer depicts people's lifestyles, behaviors, psychology, thoughts, aspirations, aspirations as a result of life depictions. This represents the space and time that moves through the whole series of events that take place in the plot of the work of art.

Odil Yakubov, who became famous as a great novelist, has a wide range of aesthetics and a deep level of vital perception, a complex expression and a colorful image. In particular, in the novels "If the Earth Works", "Ulugbek's Treasure", "Religion", "Old World", "Swans, White Birds", "Address of Justice", "Rebellious Slave", the author describes the beginning and end of humanity, the relationship between man and society. interprets the concepts of conflict, morality, and value through an artistic chronotope.
\end{abstract}

\section{Main part}

"In the literary-artistic chronotope it is possible to perceive the signs of space and time as a whole and clearly. Here time tightens, turning into an artistic gaze; and space accelerates and expands within the movement of time, plot, and history. When the signs of time appear in space, space is measured and understood in time. The nature of the artistic chronotope is reflected in the flow of such mixed symptoms "[1, pp. 43-44].

In this sense, the integral unity of artistic space and time also embodies the nature of the genre. True, novel thinking primarily harmonizes the independence of the artistic form. Given that the genre integrates the spirit of the period, the essence of the matter becomes even clearer. The artistic interpretation of the epic field leads to the subordination of space and time to the system of events in it, the world of images to the creative laws, as well as to the formation of artistic integrity, compositional continuity. While the different appearances of an artistic chronotope appear in a particular time, it requires great skill on the part of the creator to ensure a deep understanding of the unity of space and time, the reality of the wall, and interdependence in interpretation. In a work of art, space and time have a unique place, without these categories it is impossible to imagine the plot, the composition of the work. While the artistic image itself, which moves in the reality of the work, moves in a certain time and place, this situation is more deeply expressed in the historical novel. Of course, here we are far from the idea that there is no interpretation of space and time in a work on a modern theme, because, as noted above, it is impossible to imagine a work of art without space and time. "As long as man is at the heart of literature, he attains artistic perfection through the chronotope" [2, p. 58].

Indeed, the expression of the artistic chronotope in a historical novel, along with works of art, is inextricably linked with the coverage of history. This reflects the artistic character of the heroes of the work, the world of images in the process of artistic interpretation of their spiritual suffering. This is also related to the social environment in which any artistic hero has acted and is moving. "Every artist has a different approach to their time and the time in the work. For example, Chingiz Aitmatov's "Day of the Century" reflects the events that took place at the same time, and Leo Tolstoy's novel "War and Peace" depicts the events of a great period, many images typical of an epic work. It is also interpreted in Abdulla Kadyri's "Last Days" and Odil Yakubov's "Treasure of Ulugbek" [3, p. 42]. It is worth noting that each novel is a unique combination of space and time, which takes place in the compositional integrity of the work in a similar way to the art.

In the novel "Treasure of Ulugbek" by the talented writer Odil Yakubov, the artistic chronotope provides the events of the work, the world of images, the formation of character. Bright memories of Mirzo Ulugbek or other images, painful images of monologue consciousness are expressed in space and time and are recognized as one of the important factors determining the accuracy of the heroes of the work. The author connects the present 
and early memories first in order to ensure the logical continuity of events. More precisely, in the play, the tension of the time contradicts the objective reality. The writer absorbs the internal logical connection between the multilayered image (the protagonist and the social environment) into the course of events. While the events in the work reveal an artistic conflict in space and time, it served to vividly express the hero's psyche, the anguish of the soul. The novel "Treasure of Ulugbek" reflects the complex historical conditions of the period, as well as complex artistic heroes.

As noted by the literary critic Hakimjon Karimov: "In addition to expressing the idea of the writer, giving the spirit of history, he painted a clear picture of events, defined the time and place, as well as created the brightness and vitality of the heroes" [4, p. 254]. As the events of the time take shape, a fierce storm begins to engulf the heroes of the work. If at the heart of any historical reality is the intensity of space and time, it can be observed that it is also the basis for the formation of human character.

Literary critic A. Rasulov spoke about the artistic hero, who, along with the peculiarities of human character, rose to the level of character: "Man grows, changes, is formed, becomes spiritually rich. But man does not completely change, acquire a second "I", does not lose his identity, that is, a set of social relations takes place at the center of human nature, nature. To be more precise, there is a nature in which man changes, adapts, changes, changes. Hence, a unique, important core absorbs social relations. Literary character is understood as the sum of the core (fitrat, tiynat) and social relations "(pp. 5, 9).

Indeed, fiction, while creating characters, substantially reveals the spiritual world of the protagonist, the contradictions within him, formed on the basis of various life contradictions. In this regard, if we look at the novel "Treasure of Ulugbek" by Odil Yakubov, who made a huge contribution to the development of Uzbek prose, he was able to skillfully interpret the controversial life of Ulugbek Mirzo, a great talent, just ruler and scholar. Despite the complex contradictions of that time, he fought hard for the development of science in difficult conditions. As a result, he struggles with the contradictions in the inner world, in an organic unity with the struggles of life. It is in such conditions that the character of the heroes of the work is formed. Therefore, A. It is no coincidence that when Rasulov described Ulugbek as a "perfect psychological character in the novel," he recognized the image of a person who was formed on the basis of the events in the plot and rose to the level of a character. Character is distinguished by the fact that it combines the mental and physical characteristics of man, formed under the influence of the social environment. Demonstrates its character traits under the influence of the personal social environment. There are characters in life who transfer their influence to the environment, or become victims of that environment. In the novel "The Treasure of Ulugbek" we see that the dialectical unity of spiritual interpretation is expressed in close connection with the character formed on the basis of historical conditions: "-Tonight... Tonight in my dream... I saw the Master... -In my dream... the heavenly master set fire to the fireplace. They said that you turned away from science because of this unfaithful kingdom. They said, "You have lost such a mature potential in order to become the owner of the throne." (P. 6, 11). It is clear from the images that the conflicting experiences in the hero's psyche reflect his character traits, his hard work in the path of science, his conflicting struggles for the kingdom. Mirzo Ulugbek accurately describes the struggle of two opposing poles, the kingdom and science, in one heart.

In the novel, Mirzo Ulugbek uses the image of a dream not only to illuminate the psyche, but also to reveal the spiritual, spiritual world of Abdulatif Mirzo, because it is a tool that characterizes the hero psychologically. Through the dream, the writer interprets the inner world of the protagonists, the contradictions and experiences in the spiritual world, and illuminates the contradictory spiritual world of Abdulatif Mirza's suffering through mental torture through a dream episode. It also tells of the tragic fate of the prince who caused the death of his father, and is based on the process of becoming a victim of his dreams. Amir Jondar, one of Mirzo Ulugbek's most trusted emirs, betrayed him and turned to Abdulatif Mirzo. But he later regrets his actions: "Lord! This means that I escaped from the rain and was caught in a hailstorm. Isn't this a punishment for the innocent beheading and shedding of the blood of His Majesty the King of trade and regrets?" a painful thought passes through his mind. Soon, Abdulatif began to organize a conspiracy against Mirza. This is illustrated by the interpretation of a dream: 'I used to hunt deer and walk in the mountains like your faithful servant. I brought a deer's head that day! If you eat it, you will be free from all strangers and diseases, and you will be as light as a bird, a refuge! .. - All your ailments will be cured, taste it, a refuge! The prince took the bar and opened the table. In the golden barkash, his own head, stained with blood, is smiling!.. The barkash fell from his hand and his blood-stained head fell to the ground "(pp. 6, 301-302).

From the interpretations of character and spirit in the novel, it is clear that at the heart of the images is the night - a symbol of darkness and ignorance, and the earth - a place that brings man back to himself. We would like to emphasize that the concept we want to note includes all the interpretations of the chronotope in the work, as well as the realities of life - the contradictions in the human heart, the changes in thinking.

Also in the play, the concept of artistic chronotope is expressed in beautiful plates. Because the work of art reflects the contradictions in the social life of a certain period and personal experiences through the interpretation of time and space. Without these categories, it is difficult to imagine the plot and composition of the work.

Historical epoch is one of the traditional types of literary epoch and has its own aspects of appearance in a work of art. Although revolutionary history is extensive, time is shortened, the plot of the work is limited to events, which, in turn, become important step by step in the life of the people. As a result of the integral connection of 
time and space assimilated in the works of art, along with a series of life events, various qualities of the people of the period are highlighted. This feature is called the chronotope term. This concept is accepted in the literature as a "metaphor".

It is important that time and space are reflected together in a work of art. Time is a quarter of space. In a literary-artistic chronotope, there are places where the signs of space and time are connected or joined together, which serves to fully understand the idea. The character properties of time are revealed within space. Space is measured by observation time. Time is artistically manifested in this place in a strictly short and fruitful form. Space, on the other hand, accelerates and condenses, accelerating the process of movement of time, plot, and historical development. In fiction, time plays a key role in the beginning and leadership of the movement. Because the chronotope as a formal-semantic concept is the basis for the creation of the image of man in literature. In the literature, only the complicated and studied aspects of the selection of a specific historical chronotope are covered. The reality of life is reflected on the basis of concepts related to historical conditions. When we talk about "time" in a work of art, first of all, we focus on its role in the plot function. It is also recognized that the function of accelerating or, conversely, slowing down the flow of narration can, in some cases, have a direct and indirect effect on the reader's perception "[7, pp. 200-201]. Time and space have a unique character in a work of art. The authors of historical works pay serious attention to the depiction of time, no matter what time and place they refer to. This reflects the nature of the work of art more deeply: "The concept of time and space, including the description of the diverse world of images created in works of art, also has a figurative character. In any art, the interpretation of time and space is the embodiment of figurative and expressive meanings "[8, p. 31]. 3.

Historical time has a special place in each layer of epic time. In this sense, the historical epoch is a time when literature never ends. It always manifests itself in a broad and multifaceted way. Let's pay attention to the image of time in the novel "Treasure of Ulugbek". In these images, the time in the artistic text is not limited to the image of the year, but also shows that the seasons, months, weeks, days, nights, and even minutes and seconds have their own artistic function. These artistic elements form the plot of the work and serve to illuminate the actions of the images, their psychology. This can be seen in the following text:

"It's past midnight," he said. The observatory is in deep silence. As usual, Mawlana Alouddin Ali ibn Muhammad Kushchi, who was observing the celestial states at night, got up with a slight discomfort in his body. But he did not have time to put the tools in his hand, so that somewhere above, in the first kitchen, the sound of footsteps could be heard. These sounds were not like the shapeless steps of an observatory student's science, but reminiscent of the unstoppable steps of soldiers. Mevlana awoke and looked out of the window of the upper kitchen at the small carved door, and in the dimly observatory there was a thick and sharp sound:

- Mawlana Ali ibn Muhammad Kushchi! Hazrat Mirzo Ulugbek Koragoni, a talented man from Shahriyori, has commanded that you be present at the Kuksaroy immediately! ”[6, pp. 130-131].

In a play built on psychological integrity, the psyche of the image grows out of the integrity of artistic space and time. The first pages of the novel begin with an image of artistic time. These images show the conflicting aspects of the social environment, the period. When the writer chooses real historical figures as heroes, he subjugates the artistic development of the character to the unity of "novel time" (M.M. Bakhtin). It is noteworthy that in the process of interpretation, language passes to character and character to language: "It was Friday. On the occasion of Mirzo Ulugbek's entry into Herat, all the clergy, the arch-army and the arch-state mosque had gathered in the mosque. Mirzo Ulugbek, surrounded by the nobles and nobles of Herat, came out of the Madrasa Shahrukh and passed through the room of the Qalandar who had built the qibla. bet]. Artistic time leads in the interpretation of Mirzo Ulugbek's heartaches. "It was Friday" is a great day, and there is a mystery in the dervish's actions. The duration of the growth and change of events in the novel is determined by the connection that is formed between the artistic space and time. This situation is also substantiated by the images mentioned above.

A chronotope is a concept that provides plot movement and centralizes image scales. In other words, the unit of time that provides the vastness and variety of geographical space and the continuity of reality represents its essence. It is well known that human life is determined by the demands of circumstances. The image of the environment therefore serves as an artistic criterion of historical coverage. More precisely, in a historical play, character and will, personality and responsibility, desire and opportunity develop in relation to the conditions in which the protagonist lives and acts. Man changes his capabilities under environmental pressure. Every reality in the novel is deepened in time and space. Deepens the life of the heroes of art, their spiritual image, the contradictions in the spiritual world:

"Ali Kushchi, who came to the courtyard near the Oqsaroy that day, left the house dressed warmer after the afternoon prayer. He was determined to see Mawlana Muhiddin. No matter how much Mawlana Muhiddin betrayed him, no matter how much he went to the lowlands worthy of his name, Ali Kushchi could not bear to hear that he was insane and chained. After all, they had been doing it for almost a quarter of a century, studying in a madrassa. For one reason or another, the rumors about Mawlana Muhiddin made him tremble. At the same time, when he heard rumors about the madness of Mawlana Muhiddin, in particular, about the burning of blasphemous books in the observatory and what he had said to Nizamiddin Hamush and the prince, the same old thoughts came to Ali Qushchi's mind: words are invalid! Good for good, evil for evil is the return! And yet... But these thoughts evoked in his heart not the rebellious feelings of the day of the show, but rather the sad feelings of the past. Hayhot! What if an intelligent scholar like Mawlana Muhiddin, who has reached great heights in the field of sharpness, 
astrology and science and mathematics, does not know or is afraid to know this truth? " [Pp. 6, 322-323].

The author analyzes the tragic life of Mirzo Ulugbek in connection with the Oqsaroy. The writer makes effective use of the historical artistic conflict manifested between environment and conditions, space and time. This also reflects the truth of history in its interpretation of historical reality. In particular, the father-son conflict, the scholar-king conflict, the disagreement between science and religion raise the level of artistic conflict in the course of events and force the protagonist to consciously look at his own life. Especially in the interpretation of Ulugbek's personality, there is a series of emotional upheavals. It allows both internal and external contradictions to be incorporated into the course of events in the formation of his character. Ali Qushchi, one of the scholars, said that the life of Rumi in Qazizah was a little easier because they were just scientists. Ulugbek, on the other hand, was both the leader of those who saw the power of the king-humanity only in the sword, and the scholar - to continue on the right, true path to the future. It can be said that Ulugbek fully illuminates his heart in the live observation of the work.

\section{Conclusion}

In the process of interpretation, Odil Yakubov often reveals the atmosphere of that period through the image of space. At the same time, based on logical argument, the reality of the period, the social environment sheds light on various contradictions. To prove our point, let's look at the battles between Abdullatif and Mirzo Ulugbek. As much as it is a disgrace for a great figure to go to war with his child, he feels deeply that replacing the instrument of knowledge with a weapon is just as tragic, but the fate of the kingdom forces the social environment to take up arms. Even then, the desire remains in the heart of the scientist. But the wish of a great scientist does not come true. Because the environment is already tense. There is no room for compromise. If these ideas are taken more seriously, the politics of that period, the interpretation of the tragedy of the loss of the people, the contradictions in the inner world, the mental anguish. The epic field reveals the features of poetic logic, in which reality gradually fills the protagonist's activity. Therefore, there is a consistency in the description of the life of the great scientist Mirzo Ulugbek in close connection with the history of the country and the people. Historical time, spatial expression includes the literary unit, category and types of time, and gives an appearance through them. In large epic forms, the historical epoch in the poetics of the literary age reveals the historical space. The depiction of the historical epoch in the art of speech enhances its role in the lives of literary heroes with the distinctive features of their epoch. The character of the heroes is not only enriched, strengthened, motivated by the unit of time, historical time, but they, in turn, change a certain time, a real historical time. In particular, the geographical naming of places, accuracy, historical reality of the time, and even the presence of separate images with a living, real prototype, as well as the appearance of historical figures in individual literary heroes determine the dynamics of the work.

\section{References:}

1. Mikhail B. Time and chronotope forms in the novel. Essays on historical poetics (translated from Russian by Uzak Jurakulov). -Tashkent, Akademnashr, 2015. - 288 B.

2. Serif Aktash. Introduction to novel art and novel insemination. - Ankara, 1991. - 162 B.

3. Nasirov A. Art and life reality. - Istanbul, "Kesit" 2019. 140 B.

4.Izzat Sultan. Literary theory. - T., "Teacher", 2005. -272 p.

5. Rasulov A. Art is a novelty. -T., "Sharq", 2007. - 336 p.

6.Yoqubov O. Ulugbek's treasure. Roman. -T., 1994. -336 p.

7. Molchanov V.V. Vremya kak priem mistifikatsii chitatelya v sovremennoy zapodnoy literature. Rhythm of space and time in literature and art. -L .: «Nauka», 1974. -S. 290.

8. Kagan M.S. Space and time in art as a problem of aesthetic science. Rhythm of space and time in literature and art. - L .: «Nauka», 1974. - S. 310. 